\title{
Erratum to: Major metacestodes in small ruminants slaughtered at Dessie municipal abattoir, Eastern Ethiopia: prevalence, cyst viability, organ distribution and economic implications
}

Habtamu Tesfaye • Abadi Amare • Shahid Nazir • Ahmed Yasine

Published online: 2 August 2014

(C) Springer-Verlag London 2014

Erratum to: Comparative Clinical Pathology

DOI 10.1007/s00580-014-1964-0

The original version of this article contained a mistake on the list of the author group.

Correct authors are listed below.

Habtamu Tesfaye, Abadi Amare, Shahid Nazir, Ahmed

Yasine

The online version of the original article can be found at:http://dx.doi.org/ 10.1007/s00580-014-1964-0. 